\title{
Article
}

\section{Side to side differences in hamstring muscle kinematics during maximal instep soccer kicking}

Sinclair, Jonathan Kenneth

Available at http://clok.uclan.ac.uk/12583/

Sinclair, Jonathan Kenneth ORCID: 0000-0002-2231-3732 (2015) Side to side differences in hamstring muscle kinematics during maximal instep soccer kicking. Movement \& Sport Sciences . ISSN 2118-5735

It is advisable to refer to the publisher's version if you intend to cite from the work.

For more information about UCLan's research in this area go to http://www.uclan.ac.uk/researchgroups/ and search for < name of research Group>.

For information about Research generally at UCLan please go to http://www.uclan.ac.uk/research/

All outputs in CLoK are protected by Intellectual Property Rights law, including Copyright law. Copyright, IPR and Moral Rights for the works on this site are retained by the individual authors and/or other copyright owners. Terms and conditions for use of this material are defined in the policies page.

\section{CLoK}

Central Lancashire online Knowledge www.clok.uclan.ac.uk

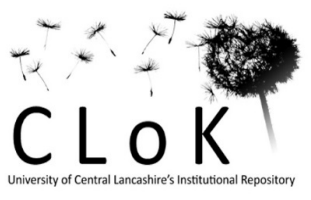




\title{
Side to side differences in hamstring muscle kinematics during maximal instep soccer kicking
}

\author{
Jonathan Sinclair \\ Division of Sport, Exercise and Nutritional Sciences, School of Sport Tourism and Outdoors, University of Central Lancashire, \\ UK
}

Received 26 June 2015 - Accepted 29 September 2015

\begin{abstract}
Hamstring strains are a common non-contact injury in soccer. The current study investigates bilateral differences in hamstring kinematics during maximal instep kicking. Thirteen male soccer players performed maximal instep kicks with their dominant and non-dominant limbs. Muscle-tendon kinematics of the four hamstring muscles during the kick movement were quantified using OpenSim software. Differences between dominant and non-dominant limbs were examined using paired t-tests. The results revealed that the biceps femoris long head (dominant $=165.28 . \pm$ $62.46 \&$ non-dominant $=137.65 \pm 52.17 \%)$, semimembranosus $($ dominant $=220.75 \pm 43.35 \&$ non-dominant $=131.23 \pm 36.74 \%)$ and semitendinosus (dominant $=90.95 \pm 16.69 \%$ and nondominant $=80.47 \pm 15.99 \%$ ) experienced significantly greater strain when using the dominant limb. The current investigation provides key information regarding the mechanics of the hamstring group during maximal instep kicking, indicating that kicking with the dominant limb may place soccer players at increased risk from hamstring strain injury.
\end{abstract}

Key words: Hamstring, soccer, muscle-tendon, muscle strain

Résumé. Différence bilatérale dans la cinématique des ischio-jambiers lors d'une frappe au pied chez des joueurs de football masculin.

\begin{abstract}
Les blessures aux muscles ischio-jambiers sont classiques au football. La présente étude analyse les différences bilatérales dans la cinématique des ischio-jambiers lors d'une frappe du pied maximale en football. Treize joueurs de football masculins ont réalisé des frappes maximales avec leurs membres dominants et non dominants. La cinématique du complexe muscle-tendon de quatre muscles des ischio-jambiers a été analysée lors du mouvement en utilisant le logiciel OpenSim. Les différences entre les membres dominants et non dominants ont été examinées à l'aide de tests $t$ appariés. Les résultats ont révélé que les longs biceps fémoraux (côté dominant $=165,28 \pm 62,46$; côté non dominant $=137,65 \pm 52,17 \%$ ), les semi-membraneux (côté dominant $=220,75 \pm 43,35$; côté non dominant $=131,23 \pm 36,74 \%$ ) et les semi-tendineux (côté dominant $=90,95 \pm 16,69$; côté non dominant $=80,47 \pm 15,99 \%$ ) subissent plus de contraintes lorsque le membre dominant est utilisé. Ces données fournissent des informations relatives à la mécanique des ischio-jambiers pendant une frappe maximale du pied et indiquent qu'une frappe avec le membre dominant en football peut entrainer des risques accrus de blessures au niveau des ischio-jambiers.
\end{abstract}

Mots clés : Ischio-jambiers, football, muscle-tendon, blessure musculaire

\section{$1 \quad 1$ Introduction}

Instep kicking is a skill that is fundamental to soccer performance and represents the most commonly used kicking technique in soccer (Kellis \& Katis, 2007; Lees \& Nolan, 1998; Lees, Asai, Andersen, Nunome, \& Sterzing, 2010). It is important to generate high ball velocities when executing instep kicks as this improves the likelihood of scoring by reducing the amount of time that the goalkeeper has to react (Sinclair, Taylor, et al., 2014).

As part of their typical training regimen, soccer players are required to develop competency in kicking with both limbs (Carey, et al., 2001). Despite this, soccer players will typically demonstrate limb dominance in kicking mechanics (Dorge, Anderson, Sorensen, \& Simonsen, 2002; Sinclair, Fewtrell, et al., 2014). The unilateral 
nature of soccer kicking has been proposed as a contributing factor to the aetiology of injury in soccer players (Dorge, et al., 2002). In relation to most other sports soccer is associated with a high rate of injury which ranges from 3.7-29.1 injuries per 1000 hours of game and training activity (Agel, Evans, Dick, Putukian, \& Marshall, 2007). Aetiological analyses investigating injury locations in soccer have shown that $60-80 \%$ of injuries occur in the lower extremities (Agel, et al., 2007; Dick, Putukian, Agel, Evans, \& Marshall, 2007).

The majority of muscle injuries in soccer are noncontact in nature (Ueblacker, Mueller-Wohlfahrt, \& Ekstrand, 2015). Hamstring strains are known to be the most common non-contact injury in soccer (Arnason, Andersen, Holme, Engebretsen, \& Bahr, 2008; Dadebo, White, \& George, 2004; Ekstrand \& Gillquist, 1982; Ekstrand, Hagglund, \& Walden, 2011; Orchard \& Seward, 2002; Orchard, Wood, Seward, \& Broad, 1998; Seward, Orchard, Hazard, \& Collinson, 1993). Strain injuries to the hamstring muscles are characterized by pain in the posterior aspect of the thigh with accompanying damage to the hamstring muscle fibres (Verrall, Slavotinek, Barnes, Fon, \& Spriggins, 2001). Hamstring strain injuries range in seriousness from grade I which is characterized by microscopic tearing and minor loss of muscle function through to grade III which represents a full muscle rupture with complete loss of function (Blankenbaker \& Tuite, 2010). Aetiological research has shown that hamstring strains occur at a rate of $3.0-4.1$ per 1000 hours of match play and $0.4-0.5$ per 1000 hours of training (Arnason, Gudmundsson, Dahl, \& Johannsson, 1996; Arnason, et al., 2004).

Hamstring strains occur as a function of excessive muscle lengthening during eccentric contractions (Heiderscheit, Sherry, Silder, Chumanov, \& Thelen 2010; Mueller-Wohlfahrt, et al., 2013; Liu, Garrett, Moorman, \& Yu, 2012). Therefore, sports motions that require frequent hamstring muscle lengthening may serve as a precursor for aetiology of hamstring muscle strains (Garrett, 1990; Garrett, Safran, Seaber, Glisson, \& Ribbeck 1987; Mair, Seaber, Glisson, \& Garrett, 1996). Clinical research has shown that the extent of muscle fibre strain and the rate of muscle fibre lengthening are primary determinants of muscle strain injuries (Liu, et al., 2012). Therefore rapid eccentric hamstring actions that are associated with maximal velocity kicking have been linked to the aetiology of hamstring injuries in soccer players (Orchard \& Seward, 2002).

A small number of investigations have examined the kinematics of the hamstring muscle group during sports movements. Yu, et al. (2008) examined the mechanics of the hamstring muscles during sprinting. Their findings showed that the risk for hamstring muscle strain injuries is greatest during the late stance and late swing phases of overground sprinting. Higashihara, Nagano, Takahashi, \& Fukubayashi (2014) investigated the effects of forward trunk lean on hamstring muscle kinematics during sprinting. They showed that the strain load imposed on the biceps femoris long head and semimembranosus muscles was larger with forward trunk lean which lead to the conclusion that injury risk in these specific muscles may be enhanced. Similarly, Chumanov, Heiderscheit, and Thelen (2011) studied hamstring muscle strain during high velocity running. Their findings showed that the greatest strain loads exist during the swing phase of running which led to the conclusion that the hamstrings are most susceptible to injury during this phase of the gait cycle.

There is currently a paucity of information regarding the mechanics of the hamstring muscle group during kicking movements nor is there any consideration given to the potential bilateral differences that may exist in hamstring kinematics. Therefore the aim of the current study was to investigate bilateral differences in the kinematics of the hamstring group during maximal instep kicking.

\section{Methods}

\subsection{Participants}

Fifteen male soccer players $($ age $=18.20 \pm 1.0$ years; height $=1.79 \pm 0.11 \mathrm{~m}$; body mass $=74.65 \pm 5.54 \mathrm{~kg}$ ) were examined whilst performing maximal instep kicks into a regulation goal with their right (dominant) and left (non-dominant) foot. All participants were academy level players contracted to a professional club in England.

\subsection{Procedure}

Kinematic information was calculated using a ten camera motion capture system (Qualisys ${ }^{\mathrm{TM}}$ Medical AB, Goteburg, Sweden) at a rate of $500 \mathrm{~Hz}$. Each participant performed maximal in-step kicks with a $5 \mathrm{~m}$ run up into a regulation sized soccer goal. Five kicking trials were obtained from each participant from the dominant and non-dominant limbs. Dynamic calibration of the motion analysis system was performed before each data collection session.

Retroreflective markers (19 $\mathrm{mm}$ diameter) were placed at the $\mathrm{C} 7, \mathrm{~T} 12$ and xiphoid process landmarks and also positioned bilaterally onto the acromion process, iliac crest, anterior superior iliac spine, posterior super iliac spine, medial and lateral malleoli, medial and lateral femoral epicondyles and greater trochanter. This allowed the trunk, pelvis, thighs, shanks and feet to be defined. Carbon-fibre tracking clusters comprising of four nonlinear retroreflective markers were positioned onto the thigh and shank segments. Static calibration trials were obtained with the participant in the anatomical position in order for the positions of the anatomical markers to be referenced in relation to the tracking clusters/markers. 
Table 1. Hip and knee joint kinematics (means, standard deviations and 95C.I's) from the dominant and non-dominant limbs.

\begin{tabular}{|c|c|c|c|c|c|c|c|c|}
\hline & \multicolumn{3}{|c|}{ Dominant } & \multicolumn{3}{|c|}{ Non-dominant } & \multirow{2}{*}{$\begin{array}{c}\% \\
\text { Difference }\end{array}$} & \multirow{2}{*}{$\begin{array}{l}\text { Effect size } \\
\quad\left(p \eta^{2}\right)\end{array}$} \\
\hline & Mean & $S D$ & $95 \%$ C.I & Mean & $S D$ & $95 \%$ C.I & & \\
\hline \multicolumn{9}{|l|}{ Pelvis } \\
\hline Angle at footstrike $\left({ }^{\circ}\right)$ & 10.52 & 1.47 & $9.71-11.33$ & 11.52 & 1.19 & $10.86-12.18$ & 9.10 & 0.24 \\
\hline Angle at maximum hip flexion $\left(^{\circ}\right)$ & 17.63 & 1.68 & $16.69-18.57$ & 23.48 & 2.57 & $22.06-24.90$ & 28.47 & 0.25 \\
\hline Range of motion $\left(^{\circ}\right)$ & 7.11 & 1.99 & $6.01-8.22$ & 11.96 & 2.55 & $10.55-13.38$ & 50.85 & 0.40 \\
\hline \multicolumn{9}{|l|}{ Hip } \\
\hline Angle at footstrike $\left({ }^{\circ}\right)$ & -14.25 & 1.44 & $-15.03--13.45$ & -11.57 & 0.58 & $-10.98--11.06$ & 20.76 & 0.60 \\
\hline Angle at maximum hip flexion $\left(^{\circ}\right)$ & 68.55 & 7.30 & $64.50-72.59$ & 60.73 & 6.39 & $57.20-64.27$ & 12.09 & 0.35 \\
\hline Range of motion $\left({ }^{\circ}\right)$ & 82.79 & 6.60 & $79.14-86.45$ & 72.30 & 6.53 & $68.69-75.91$ & 13.53 & 0.50 \\
\hline \multicolumn{9}{|l|}{ Knee } \\
\hline Angle at footstrike $\left(^{\circ}\right)$ & 81.00 & 6.36 & $77.48-84.52$ & 81.07 & 7.91 & $76.69-85.45$ & 0.08 & 0.01 \\
\hline Angle at maximum hip flexion $\left(^{\circ}\right)$ & 39.05 & 1.98 & $21.95-44.15$ & 33.23 & 2.37 & $27.08-40.69$ & 16.10 & 0.42 \\
\hline Range of motion $\left({ }^{\circ}\right)$ & 67.95 & 6.91 & $64.13-71.78$ & 61.84 & 6.53 & $58.22-65.46$ & 9.42 & 0.23 \\
\hline
\end{tabular}

\section{$1 \quad 2.3$ Data processing}

2 Dynamic trials were digitized using Qualisys Track Man-

3 ager in order to identify anatomical and tracking mark-

4 ers then exported as C3D files to Visual 3D (C-Motion,

5 Germantown, MD, USA). Kinematic data was smoothed 6 using a cut-off frequency of $15 \mathrm{~Hz}$ with a non-phase shift 7 low-pass Butterworth 4th order filter. Five kicking trials were obtained from each participant from the dominant and non-dominant limbs. Kicking trials were defined from the instance of stance limb touch down to maximum hip flexion (R). Kinematic parameters from the kicking limb that were extracted for statistical analysis were 1) angle at stance limb footstrike, 2) angle at maximum hip flexion and 3) range of motion representing the angular range of motion from footstrike to maximum hip flexion.

OpenSim software was used to quantify muscle-tendon lengths during the kicking movements (Delp, et al., 2007). Muscle kinematics were quantified using the gait2392 model using Opensim v3.2. This model corresponds to the eight segments exported from Visual 3D and features ninety two muscles, eighty six of which are centred around the lower extremities and six are associated with the pelvis and trunk. The muscle properties were modelled using the Hill recommendations based on the associations between force-velocity-length (Zajac, 1989). These muscle properties were then scaled based on each participant's height and body mass based on the recommendations of Delp, et al., (1990). Muscle-tendon lengths are determined by the positions of their proximal and distal muscles muscle origins. The muscle-tendon complexes which were evaluated as part of the current research were the biceps femoris long head ( $\mathrm{LH})$, biceps femoris short head (SH), semimembranosus and semitendinosus. Muscle kinematic parameters that were extracted for statistical analysis were 1) change in length throughout the kicking movement 2) strain (representative of the change in length divided by original length at the start of the movement) and 3) maximum lengthening velocity.

\subsection{Statistical analyses}

39

Descriptive statistics (means, standard deviations and $95 \%$ confidence intervals) were calculated. To compare differences in hamstring muscle kinematics between the dominant and non-dominant limbs, paired t-tests were utilized with statistical significance accepted at the $p \leqslant 0.05$ level (Sinclair, Taylor, \& Hobbs, 2013). Effect sizes were quantified using partial eta ${ }^{2}\left(\mathrm{p} \eta^{2}\right)$. In addition to this percentage differences were also calculated. The Shapiro-Wilk statistic for each condition confirmed that the data were normally distributed. All statistical procedures were conducted using SPSS 22.0 (SPSS Inc., Chicago, IL, USA).

\section{Results}

\subsection{Angular kinematics}

The hip joint at footstrike was shown to be significantly $\left(p<0.05, p \eta^{2}=0.60\right)$ more extended in the dominant foot compared to non-dominant. In addition the hip was also found to be significantly $\left(p<0.05, p \eta^{2}=0.35\right)$ more extended at the instance of maximum hip flexion in the dominant limb. Finally, the hip range of motion was significantly $\left(p<0.05, p \eta^{2}=0.50\right)$ larger when using the dominant foot compared to non-dominant (Tab. 1, Fig. 1a).

The knee joint was significantly more flexed $(p<0.05$, $\left.p \eta^{2}=0.42\right)$ at the instance of peak hip flexion in the nondominant limb (Tab. 1, Fig. 1c). Finally at the pelvis, range of motion was significantly greater $\left(p<0.05, p \eta^{2}=\right.$ 0.40 ) when kicking with the non-dominant limb (Tab. 1, Fig. 1c).

\subsection{Hamstring kinematics}

For the biceps femoris LH muscle the dominant limb was associated with a significantly $\left(p<0.05, p \eta^{2}=0.47\right)$ 


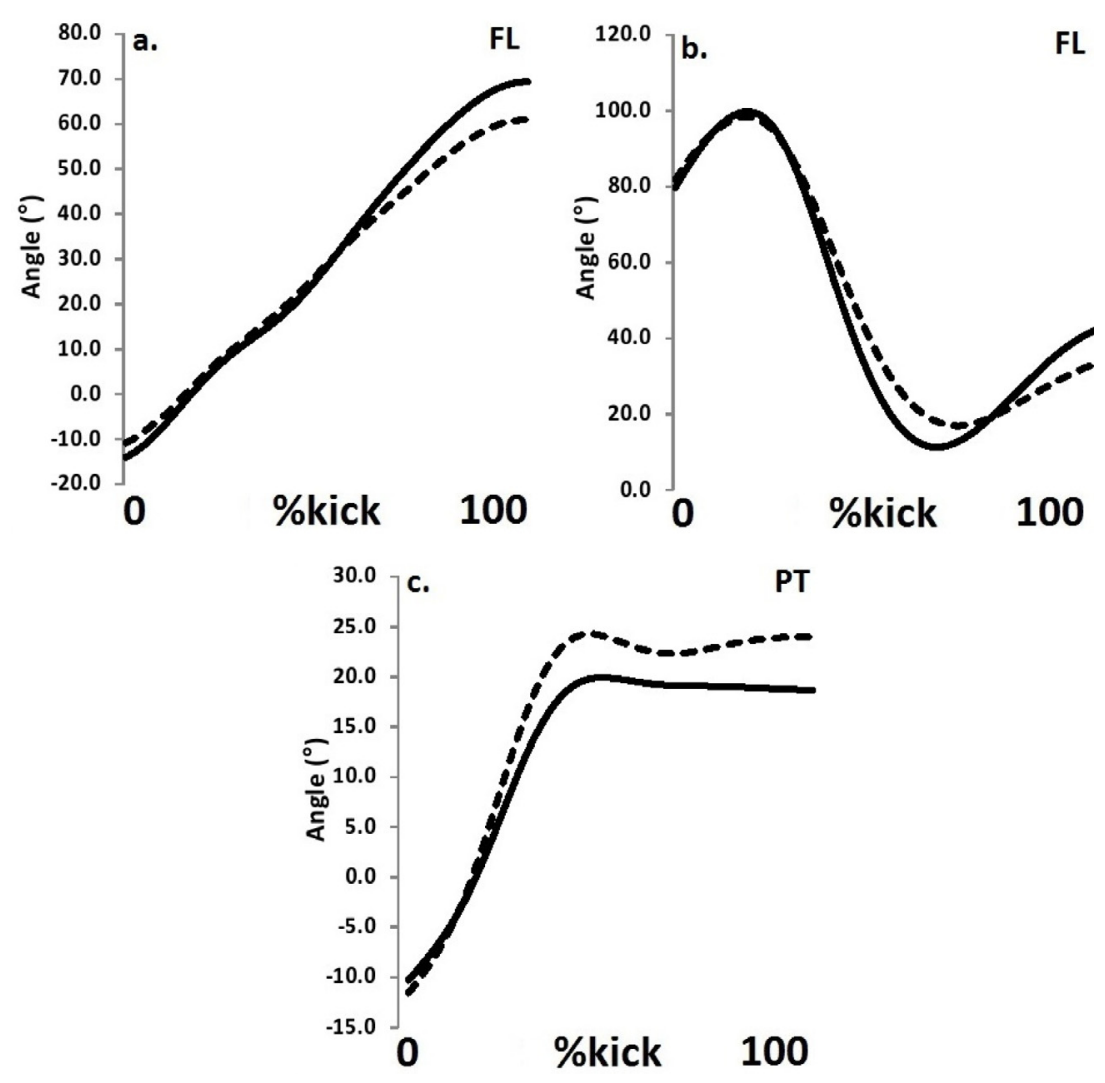

Fig. 1. Joint and segment kinematics $(\mathrm{a}=$ hip, $\mathrm{b}=$ knee and $\mathrm{c}=$ pelvis $)$ from the dominant and non-dominant limbs $(\mathrm{black}=$ dominant and dash $=$ non-dominant $)(\mathrm{FL}=$ flexion and $\mathrm{PT}=$ posterior tilt $)$.

Table 2. Hamstring kinematics (means, standard deviations and 95the dominant and non-dominant limbs.

\begin{tabular}{|c|c|c|c|c|c|c|c|c|}
\hline & \multicolumn{3}{|c|}{ Dominant } & \multicolumn{3}{|c|}{ Non-dominant } & \multirow{2}{*}{$\begin{array}{c}\% \\
\text { Difference }\end{array}$} & \multirow{2}{*}{$\begin{array}{l}\text { Effect size } \\
\qquad\left(p \eta^{2}\right)\end{array}$} \\
\hline & Mean & $S D$ & $95 \%$ C.I & Mean & $S D$ & 95\% C.I & & \\
\hline Biceps femoris LH change in length (m) & 0.34 & 0.05 & $0.30-0.40$ & 0.29 & 0.08 & $0.24-0.34$ & 15.70 & 0.47 \\
\hline Biceps femoris $\mathrm{SH}$ change in length $(\mathrm{m})$ & 0.05 & 0.02 & $0.04-0.06$ & 0.06 & 0.01 & $0.05-0.07$ & 18.27 & 0.25 \\
\hline Semimembranosus change in length $(\mathrm{m})$ & 0.36 & 0.04 & $0.34-0.38$ & 0.27 & 0.04 & $0.25-0.29$ & 29.88 & 0.71 \\
\hline Semitendinosus change in length $(\mathrm{m})$ & 0.32 & 0.03 & $0.29-3.34$ & 0.28 & 0.04 & $0.26-0.30$ & 10.95 & 0.39 \\
\hline Biceps femoris LH strain (\%) & 165.28 & 62.46 & $130.69-199.98$ & 137.65 & 52.17 & $108.76-165.54$ & 18.24 & 0.47 \\
\hline Biceps femoris SH strain (\%) & 25.76 & 10.68 & $19.85-31.67$ & 30.40 & 6.88 & $26.59-34.21$ & 16.52 & 0.24 \\
\hline Semimembranosus strain (\%) & 220.75 & 45.35 & $195.64-245.87$ & 131.23 & 36.74 & $110.89-151.58$ & 50.86 & 0.73 \\
\hline Semitendinosus strain (\%) & 90.95 & 16.69 & $81.71-100.19$ & 80.47 & 15.99 & $71.61-89.32$ & 12.23 & 0.37 \\
\hline Biceps femoris LH peak velocity $(\mathrm{m} / \mathrm{s})$ & 1.53 & 0.06 & $1.31-1.74$ & 1.55 & 0.02 & $1.39-1.68$ & 1.38 & 0.08 \\
\hline Biceps femoris $\mathrm{SH}$ peak velocity $(\mathrm{m} / \mathrm{s})$ & 1.57 & 0.18 & $1.47-1.67$ & 1.60 & 0.13 & $1.53-1.67$ & 1.30 & 0.08 \\
\hline Semimembranosus peak velocity $(\mathrm{m} / \mathrm{s})$ & 2.69 & 0.11 & $2.58-2.78$ & 2.72 & 0.10 & $2.60-2.83$ & 1.13 & 0.07 \\
\hline Semitendinosus peak velocity $(\mathrm{m} / \mathrm{s})$ & 3.20 & 0.21 & $3.08-3.33$ & 3.41 & 0.15 & $3.30-3.50$ & 6.28 & 0.22 \\
\hline
\end{tabular}

1 greater change in length compared to the non-dominant 2 limb. In addition the findings also showed that the 3 strain experienced by the biceps femoris LH was sig4 nificantly $\left(p<0.05, p \eta^{2}=0.47\right)$ greater when using 5 the dominant limb (Tab. 2, Fig. 2a). In addition for 6 the semimembranosus the dominant limb was found to 7 have undergone a significantly $\left(p<0.05, p \eta^{2}=0.71\right)$ 8 larger change in length. Also the strain experienced by the semimembranosus was significantly $(p<0.05,9$ $\left.p \eta^{2}=0.73\right)$ greater in the dominant limb compared to 10 non-dominant (Tab. 2, Fig. 2c). Finally, for the semi- 11 tendinosus the dominant limb was associated with a 12 significantly $\left(p<0.05, p \eta^{2}=0.39\right)$ larger change in 13 length. The strain experienced by the semitendinosus was 14 significantly $\left(p<0.05, p \eta^{2}=0.37\right)$ greater in the domi- 15 nant limb compared to non-dominant (Tab. 2, Fig. 2d). $\quad 16$ 

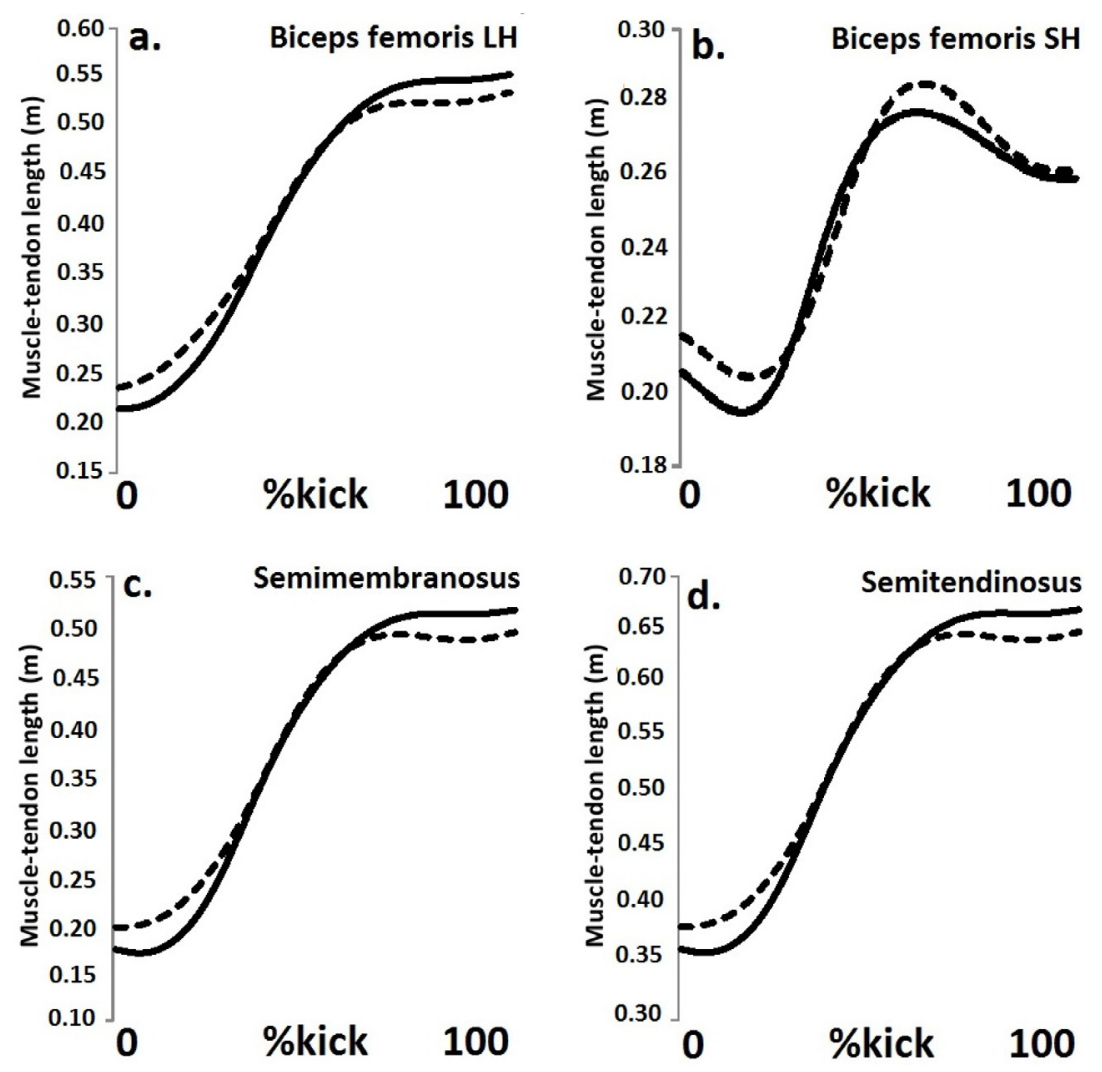

Fig. 2. Muscle-tendon lengths from the dominant and non-dominant limbs (black $=$ dominant and dash $=$ non-dominant).

\section{Discussion}

The aim of the current study was to investigate bilateral differences in the kinematics of the hamstring group during maximal instep kicking. To the authors knowledge this represents the first investigation to quantify hamstring muscle kinematics during instep kicking. A study of this nature may provide important information to soccer clinicians regarding the aetiology of hamstring strain injuries as a function of maximal kicking actions.

The first key observation is that all of the four primary hamstring muscles tested in the current study exhibited eccentric lengthening in an almost linear manner throughout the kick movement. This is to be expected given the joint observed joint/ segment kinematics during the instep kick movement; hamstring lengthening was required support flexion and extension rotations of the hip and knee joints and also the posterior tilt of the pelvic segment during the kick (Lees, et al., 2010).

Of further importance is the finding that the dominant limb was associated with significant increases in strain magnitude of the biceps femoris LH, semimembranosus and semitendinosus muscles. The strain imposed on the hamstring muscle-tendon unit during the kick is a function of the flexion and extension patterns of at the hip and knee joints (Opar, Williams, \& Shield, 2012). Given the proximal and distal attachment of the aforementioned muscles to the ischial tuberosity and fibula/ tibial heads; the increased angular range of the hip and extension of the knee joint when using the dominant limb served to enhance the strain imposed on the muscles.

Although differences in muscle strain were shown between the dominant and non-dominant limbs, the biceps femoris LH, semimembranosus and semitendinosus muscles all experienced a substantial degree of strain regardless of limb dominance. Given the proposed relationship between muscle strain magnitude and the aetiology of muscle strain injuries the current investigation provides insight regarding the high incidence of hamstring strain injuries in soccer (Orchard, et al., 1998; Orchard \& Seward, 2002; Seward, et al., 1993). Nonetheless, the statistical analysis showed that the biceps femoris LH, semimembranosus and semitendinosus muscles of the dominant limb experience significantly greater strain, leading to the conclusion that kicking with the dominant limb may place soccer players at increased risk from hamstring strain injury. Of further interest is the relatively low amount of strain experienced by muscle-tendon unit of the biceps femoris SH. It is hypothesized that this finding relates to the unilateral nature of the biceps femoris SH which attaches proximally to the lateral ridge of the femur rather as opposed to the ischial tuberosity. Therefore, this muscle unit is not involved to the same extent in hip flexion or in posterior pelvic tilt and thus the extent to which it is required to lengthen is reduced in relation to the other hamstring muscles. 

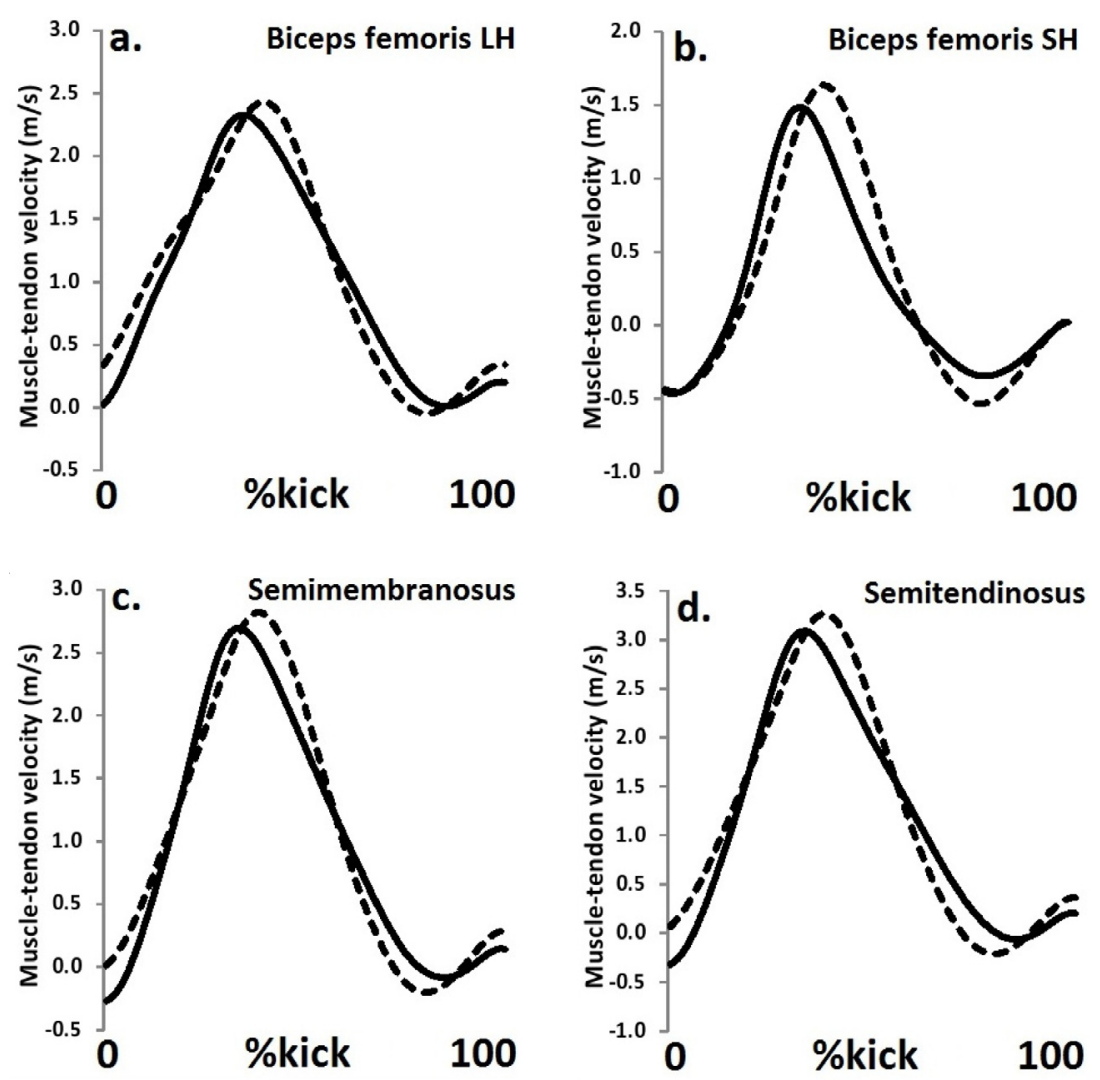

Fig. 3. Muscle-tendon velocities from the dominant and non-dominant limbs (black $=$ dominant and dash $=$ non-dominant).

There are some limitations to the current work which should be acknowledged so that the observations can be appropriately contextualized. Firstly the current investigation utilized an all-male sample which may limit its generalizability. Barfield, et al. (2002) documented gender differences in kicking kinematics during maximal instep kicking. In addition to this clinical research investigating the prevalence of sports injuries has shown that there are gender differences in hamstring injury risk (Ristolainen, et al., 2010; Sallis, Jones, Sunshine, Smith, \& Simon, 2001; Satterthwaite, Larmer, Gardiner, \& Norton, 1996). It is therefore recommended that the current investigation be repeated using a sample of female soccer players.

In addition whilst, musculoskeletal simulations have the potential to improve our understanding of muscles behaviour during movement, there are some limitations to this technique that should be recognised. Musculoskeletal simulations utilize a generic model with a number of mechanical assumptions such as constrained rotational degrees of freedom, fiber pennation angles, joint articulations and the origins and insertions of the muscle-tendons units may lead to incorrectly predicted muscle kinematics. It is also important to recognise that muscle-tendon lengthening is not necessarily linearly related to muscle fiber strain because of the interactions between tendon elasticity and muscle contraction states during movement (Zajac, 1989).
In conclusion, although the mechanics of instep kicking have been examined extensively, the current knowledge regarding the mechanics of the hamstring muscles during this movement is limited. The present investigation therefore adds to the current knowledge by providing a comprehensive evaluation of hamstring kinematics during maximal instep kicking when using the dominant and non-dominant limbs. Importantly the current study showed that the amount of muscle strain in the biceps femoris LH, semimembranosus and semitendinosus muscles was significantly larger when kicking with the dominant limb. The current investigation therefore provides key information regarding the mechanics of the hamstring group during maximal instep kicking, which shows that when kicking maximally with the dominant limb soccer players may be at greater risk from hamstring strain injury.

\section{Bibliography}

Agel, J., Evans, T.A., Dick, R., Putukian, M., \& Marshall, S.W. (2007). Descriptive epidemiology of collegiate men's soccer injuries: National Collegiate Athletic Association Injury Surveillance System, 19881989 through 2002-2003. Journal of Athletic Training, 42, $270-277$. 
1 Arnason, A., Gudmundsson, A., Dahl, H.A., \& Johannsson, E. (1996). Soccer injuries in Iceland. Scandinavian Journal of Medicine 85 Science in Sports, 6, 40-45.

Arnason, A., Sigurdsson, S.B., Gudmundsson, A., Holme, I., Engebretsen, L., \& Bahr, R. (2004). Risk factors for injuries in football. American Journal of Sports Medicine, 32, 5-16.

Arnason, A., Andersen, T.E., Holme, I., Engebretsen, L., \& Bahr, R. (2008). Prevention of hamstring strains in elite soccer: an intervention study. Scandinavian Journal of Medicine \& Science in Sports, 18, 40-48.

Barfield, W.R., Kirkendall D.T. (2002). Kinematic instep kicking differences between elite female and male soccer players. Journal of Sports Science \& Medicine, 1, 272-279.

Blankenbaker, D.G., \& Tuite, M.J. (2010). Temporal changes of muscle injury. Seminars in Musculoskeletal Radiology, 14, 176-193.

Carey, D.P., Smith, G., Smith, D.T., Shepherd, J.W., Skriver, J., Ord, L., \& Rutland, A. (2001). Footedness in world soccer: an analysis of France'98. Journal of Sports Sciences, 19, 855-864.

Chumanov, E.S., Heiderscheit, B.C., \& Thelen, D.G. (2011). Hamstring musculotendon dynamics during stance and swing phases of high speed running. Medicine \& Science in Sports \& Exercise, 43, 525-532.

Dadebo, B., White, J., \& George, K.P. (2004). A survey of flexibility training protocols and hamstring strains in professional football clubs in England. British Journal of Sports Medicine, 38, 388-394.

Delp, S.L., Loan, J.P., Hoy, M.G., Zajac, F.E., Topp, EL., \& Rosen J.M. (1990). An interactive graphics-based model of the lower extremity to study orthopaedic surgical procedures. IEEE Transactions Biomedical Engineering, 3\%, $757-767$.

Delp, S.L., Anderson, F.C., Arnold, A.S., Loan, P, Habib, A, John, C.T., \& Thelen, D.G. (2007). OpenSim: opensource software to create and analyze dynamic simulations of movement. IEEE Trans Biomedical Engineering, 54, 1940-1950.

Dick, R., Putukian, M., Agel, J., Evans, T.A., \& Marshall, S.W. (2007). Descriptive epidemiology of collegiate women's soccer injuries: National Collegiate Athletic Association Injury Surveillance System, 19881989 through 2002-2003. Journal of Athletic Training, 42, 278-285.

Dorge, H.C., Anderson, T.B., Sorensen, H., \& Simonsen, E.B. (2002). Biomechanical differences in soccer kicking with the preferred and the non-preferred leg. Journal of Sports Sciences, 20, 293-299.

Ekstrand, J., \& Gillquist, J. (1982). The frequency of muscle tightness and injuries in soccer players. American Journal of Sports Medicine, 10, 75-78.

Ekstrand, J., Hagglund, M., \& Walden, M. (2011). Epidemiology of muscle injuries in professional football (soccer). American Journal of Sports Medicine, 39, 1226-1232.
Garrett, W.E., Safran, M.R., Seaber, A.V., Glisson, R.R., \& Ribbeck, B.M. (1987). Biomechanical comparison of stimulated and non-stimulated skeletal muscle pulled to failure. American Journal of Sports Medicine, 15, 448-454.

Garrett, W.E. (1990). Muscle strain injuries: clinical and basic aspects. Medicine \& Science in Sports \& Exercise, 22, 436-443.

Heiderscheit, B.C, Sherry, M.A., Silder, A., Chumanov, E.S, \& Thelen, D.G. (2010). Hamstring strain injuries: recommendations for diagnosis, rehabilitation, and injury prevention. Journal of Orthopaedic \& Sports Physical Therapy, 40, 67-81.

Higashihara, A., Nagano, Y., Takahashi, K., \& Fukubayashi, T. (2014). Effects of forward trunk lean on hamstring muscle kinematics during sprinting. Journal of Sports Sciences, 33, 1366-1375.

Kellis, E., \& Katis, A. (2007). Biomechanical characteristics and determinants of instep soccer kick. Journal of Sports Science and Medicine, 6, 154-165.

Lees, A., \& Nolan, L. (1998). The biomechanics of soccer: A review. Journal of Sports Sciences, 16, 21-234.

Lees, A., Asai, T., Andersen, T.B., Nunome, H., \& Sterzing, T. (2010). The biomechanics of kicking in soccer: A review. Journal of sports sciences, 28, 805-817.

Liu, H., Garrett, W.E., Moorman, C.T., \& Yu, B. (2012). Injury rate, mechanism, and risk factors of hamstring strain injuries in sports: A review of the literature. Journal of Sport and Health Science, 1, 92-101.

Mair, S.D., Seaber, A.V., Glisson, R.R., \& Garrett, W.E. (1996). The role of fatigue in susceptibility to acute muscle strain injury. American Journal of Sports Medicine, 24, 137-143.

Mueller-Wohlfahrt, H.W., Haensel, L., Mithoefer, K., Ekstrand, J., English, B., McNally, S., \& Ueblacker, P. (2013). Terminology and classification of muscle injuries in sport: a consensus statement. British Journal of Sports Medicine, 4\%, 6, 342-350.

Opar, M.D.A., Williams, M.D., \& Shield, A.J. (2012). Hamstring strain injuries. Sports Medicine, 42, 209-226.

Orchard, J., Wood, T., Seward, H., \& Broad, A. (1998). Comparison of injuries in elite senior and junior Australian football. Journal of Science \& Medicine in Sport, 1, 83-88.

Orchard, J., \& Seward, H. (2002). Epidemiology of injuries in the Australian Football League, seasons 1997-2000. British Journal of Sports Medicine, 36, 39-44.

Ristolainen, L., Heinonen, A., Turunen, H., Mannström, H., Waller, B., Kettunen, J. A., \& Kujala, U.M. (2010). Type of sport is related to injury profile: A study on cross country skiers, swimmers, long-distance runners and soccer players. A retrospective 12-month study. Scandinavian Journal of Medicine \& Science in Sports, 20, 384-393.

Sallis, R.E., Jones, K., Sunshine, S., Smith, G., \& Simon, 108 L. (2001) Comparing sports injuries in men and women. 109 International Journal of Sports Medicine 22, 420-423. 70

\section{2} 103 104 105 106 107 竞的 110 
1 Satterthwaite, P., Larmer, P., Gardiner, J., \& Norton, R. (1996). Incidence of injuries and other health problems in the Auckland Citibank marathon, 1993. British Journal of Sports Medicine, 30, 324-326.

Seward, H., Orchard, J., Hazard, H., \& Collinson, D. (1993). Football injuries in Australia at the elite level. The Medical Journal of Australia, 159, 298-301.

Sinclair, J., Taylor, P.J., \& Hobbs, S.J. (2013). Alpha level adjustments for multiple dependent variable analyses and their applicability-a review. International Journal of Sports Science \& Engineering, 7, 17-20.

Sinclair, J., Fewtrell, D., Taylor, P.J., Atkins, S., Bottoms, L., \& Hobbs, S.J. (2014). Three-dimensional kinematic differences between the preferred and non-preferred limbs during maximal instep soccer kicking. Journal of Sports Sciences, 32, 1914-1923.

Sinclair, J., Taylor, P.J., Atkins, S., Bullen, J., Smith, A., \& Hobbs, S.J. (2014). The influence of lower extremity kinematics on ball release velocity during in-step place kicking in rugby union. International Journal of Performance Analysis in Sport, 14, 64-72.
Ueblacker, P., Mueller-Wohlfahrt, H. W., \& Ekstrand, J. (2015). Epidemiological and clinical outcome comparison of indirect ('strain') versus direct ('contusion') anterior and posterior thigh muscle injuries in male elite football players: UEFA Elite League study of 2287 thigh injuries (2001-2013). British Journal of Sports Medicine, doi:10.1136/bjsports-2014-094285.

Verrall, G.M., Slavotinek, J.P., Barnes, P.G., Fon, G.T., \& Spriggins, A.J. (2001). Clinical risk factors for hamstring muscle strain injury: a prospective study with correlation of injury by magnetic resonance imaging. British Journal of Sports Medicine, 35, 435-439.

Yu, B., Queen, R.M., Abbey, A.N., Liu, Y., Moorman, C.T., \& Garrett, W.E. (2008). Hamstring muscle kinematics and activation during overground sprinting. Journal of Biomechanics, 41, 3121-3126.

Zajac, F.E. (1989). Muscle and tendon: properties, models, scaling, and application to biomechanics and motor control. Critical Reviews in Biomedical Engineering, 17, 359-411. 